\title{
Toll-like receptor 4 in glial inflammatory responses to air pollution in vitro and in vivo
}

\author{
Nicholas C. Woodward' ${ }^{1}$, Morgan C. Levine ${ }^{2}$, Amin Haghani ${ }^{1}$, Farimah Shirmohammadi ${ }^{3}$, Arian Saffari ${ }^{3}$, \\ Constantinos Sioutas ${ }^{3}$, Todd E. Morgan ${ }^{1}$ and Caleb E. Finch ${ }^{1,4^{*}}$
}

\begin{abstract}
Background: Exposure to traffic-related air pollution (TRAP) is associated with accelerated cognitive aging and higher dementia risk in human populations. Rodent brains respond to TRAP with activation of astrocytes and microglia, increased inflammatory cytokines, and neurite atrophy. A role for Toll-like receptor 4 (TLR4) was suggested in mouse TLR4-knockouts, which had attenuated lung macrophage responses to air pollution.
\end{abstract}

Methods: To further analyze these mechanisms, we examined mixed glial cultures (astrocytes and microglia) for RNA responses to nanoscale particulate matter (nPM; diameter $<0.2 \mu \mathrm{m}$ ), a well-characterized nanoscale particulate matter subfraction of TRAP collected from a local freeway (Morgan et al. Environ Health Perspect 2011; 119,1003-1009, 2011). The nPM was compared with responses to the endotoxin lipopolysaccharide (LPS), a classic TLR4 ligand, using Affymetrix whole genome microarray in rats. Expression patterns were analyzed by significance analysis of microarrays (SAM) for fold change and by weighted gene co-expression network analysis (WGCNA) to identify modules of shared responses between nPM and LPS. Finally, we examined TLR4 activation in hippocampal tissue from mice chronically exposed to nPM.

Results: SAM and WGCNA analyses showed strong activation of TLR4 and NF-KB by both nPM and LPS. TLR4 siRNA attenuated TNFa and other inflammatory responses to nPM in vitro, via the MyD88-dependent pathway. In vivo, mice chronically exposed to nPM showed increased TLR4, MyD88, TNFa, and TNFR2 RNA, and decreased NF-KB and TRAF6 RNA TLR4 and NF-KB responses in the hippocampus.

Conclusions: These results show TLR4 activation is integral in brain inflammatory responses to air pollution, and warrant further study of TLR4 in accelerated cognitive aging by air pollution.

Keywords: Air pollution, Nanoparticulate matter, Microglia, Astrocytes, TLR4, NF-kB, TNFa, Cell culture, Hippocampus

\section{Background}

Traffic-related air pollution (TRAP) is associated in human populations with accelerated cognitive aging [1-4] and increased risk of dementia [5-8]. Exposure to high levels of fine particulate matter $\left(\mathrm{PM}_{2.5}\right)$ in older adults is associated with greater cognitive decline, equivalent to 2 years of normal cognitive aging $[9,10]$, and developmental exposure to

\footnotetext{
* Correspondence: cefinch@usc.edu

${ }^{1}$ Leonard Davis School of Gerontology, University of Southern California, Los Angeles, CA, USA

${ }^{4}$ Dornsife College, University of Southern California, Los Angeles, CA, USA

Full list of author information is available at the end of the article
}

TRAP is associated with delayed and impaired cognitive development $[11,12]$.

TRAP-associated changes of normal aging include decreased white and grey matter [13, 14], while post mortem samples from a highly polluted Mexican City showed white matter hyperintensities and neuroinflammation $[15,16]$. Rodent models given controlled exposure to TRAP particulate material (PM), showed corresponding loss of dendritic spines [17] and microglial activation $[18,19]$. Brain inflammatory responses include increased IL- $1 \alpha$ and TNF $\alpha[17,18,20]$, together with NF$\kappa B[21]$ and detoxifying enzymes associated with Nrf2 
[22]. In our model, mice were chronically exposed to nPM, a nano-scaled subfraction of TRAP $[18,23]$.

Airborne PM is defined by three size classes: coarse, $\mathrm{PM}_{10} ;<10 \mu \mathrm{m}$ diameter; fine, $\mathrm{PM}_{2.5} ;<2.5 \mu \mathrm{m}$; and ultrafine, $\mathrm{PM}_{0.2} ;<0.2 \mu \mathrm{m}$. The $\mathrm{PM}_{0.2}$, though not EPA regulated, have more toxicity and greater redox activity than larger size fractions [24]. In rodents, in vivo exposure to $\mathrm{PM}_{0.2}$ shows their penetration into the brain via the nose $[25,26]$. The present studies use a nano-sized watersoluble subfraction of $\mathrm{PM}_{0.2}(\mathrm{nPM})$ with strong redox and inflammatory activity in vitro and in vivo that induced microglial activation TNF $\alpha$ and other cytokines associated with oxidative stress [24, 27].

To further study glial roles, we used an in vitro model of mixed glia (astrocytes and microglia), in which nPM induced TNFa induction with well-defined dose response [27]. In media from nPM-treated glia, primary neurons had shorter neurites and fewer growth cones; these nPM effects were mediated by the TNF $\alpha$ receptor TNFR1 [27]. We hypothesized further that these mechanisms involve a priori genes of interest NF-kB and TLR4 (Toll-like receptor 4), through MyD88-dependent pathways, shown for lung macrophage responses to TRAP $[28,29]$. TLR4 has over 30 known ligands [30]. Its role in inflammatory pathways may include neuroprotective functions, e.g., by increasing amyloid $\beta$-peptide uptake by microglia [31]. While a TLR4 response to air pollution has been hypothesized, its exact involvement remains unclear, as TLR4 mutant individuals still showed immune cell response to PM [16].

These questions were agnostically approached by Affymetrix microarray in mixed glia cultures for responses to $\mathrm{nPM}$ and to lipopolysaccharide (LPS). The endotoxin LPS is relevant to TRAP induced inflammatory responses. While nPM does not contain endotoxin [32], the larger sized PM have endotoxin activity [33], whereas the TLR4 pathway is necessary for LPS responses. Our findings were compared with LPS responses of BV-2 microglial cells $[34,35]$ and primary cultured microglia [36].

Two bioinformatics approaches were used: fold changes in RNA expression were identified by significance analysis of microarrays (SAM) and shared modules of RNA responses between LPS and nPM were identified by weighted gene co-expression network analysis (WGCNA), which has advantages over differential expression analysis. WCGNA enables the reduction of high-dimensional data into fewer variables for analysis of shared responses between treatments. While both SAM and WGCNA identify larger responses, WGCNA also identifies subtler interactions within a network. WGCNA provides further insight into the relationships between genes, extending beyond known pathways [37].

Following SAM and WGCNA, we analyzed transcription factor target (TFT) enrichment and upstream regulators. Finally, bioinformatics findings were verified in vitro by siRNA experiments with mixed glia and in vivo with hippocampal RNA from mice exposed to nPM.

\section{Methods \\ Animals and ethics statement}

Pregnant Sprague Dawley rats, from Envigo (Livermore, CA, USA) and C57BL/6J female mice, from the NIA Aged Rodent Colony (Charles River Labs) were maintained under standard conditions according to $\mathrm{NIH}$ guidelines. Protocols were approved by the University of Southern California Institutional Animal Care and Use Committee.

\section{Collection of nanoscale particulate material (nPM)}

The $\mathrm{nPM}$ utilized in these studies are a nanoscale subfraction of TRAP ( $<200 \mathrm{~nm}$ diameter) collected from urban air in Los Angeles near the CA-110 Freeway using a high-volume impactor sampler [38]. These aerosols represent a mix of fresh ambient PM mostly from vehicular traffic $[39,40]$. nPM was collected continuously for 5 weeks on Teflon filters, followed by resuspension in deionized water by vortexing and sonication [18]. The nPM comprised approximately $20 \%$ by mass of ambient $\mathrm{PM}_{2.5}$ in that location [41]. Water-soluble metals and organic compounds were efficiently transferred from the filter into aqueous suspension for exposures [18]. Relative to the total filter-trapped ultrafines $\left(\mathrm{PM}_{0.2}\right)$, the nPM subfraction eluted into aqueous phase was depleted in black carbon and water-insoluble organic compounds [18]. Stock nPM solution had trace endotoxin levels (2.5 $\mathrm{EU} / \mathrm{mL}$ by Limulus amoebocyte assay) compared to that eluted from filter collected ambient air $(2.0 \mathrm{EU} / \mathrm{mL})$. Treatment levels were $0.05-0.08 \mathrm{EU} / \mathrm{mL}$, equivalent to sterile water (FDA 2015). These low EU levels are consistent with the negligible endotoxin activity in ultrafine PM (below Limulus assay threshold) [32]. Frozen stocks at $20{ }^{\circ} \mathrm{C}$ retain chemical stability for $>30$ days, including long-lived free radicals $[18,24]$. The $\mathrm{nPM}$ was reaerosolized to an airborne concentration of $300 \mu \mathrm{g} / \mathrm{ml}$. Mice (3 month old) were exposed to nPM or filtered air for $150 \mathrm{~h}$ during 10 weeks ( $5 \mathrm{~h} /$ day, 3 days/week).

\section{Tissue collection}

One month after exposure, mice were anesthetized by isoflurane and saline perfused. One hemisphere was cryosectioned for histochemistry and the other, microdissected by brain region.

\section{Cell culture}

Primary mixed glia (microglia and astrocytes) were cultured from neonatal postnatal day 3 rat cerebral cortex (mixed sex, Sprague Dawley; Envigo, Livermore, CA). Mixed glial cultures were used because some astrocyte responses to LPS are microglial dependent [42, 43]. 
Mixed glial cultures were 3:1 astrocytes to microglia [27]. Cerebral cortex was mechanically dissociated, strained by a 70- $\mu \mathrm{m}$ Millipore filter, and plated onto 75$\mathrm{cm}^{2}$ cell culture flasks in Dulbecco's modified Eagle's medium/F12 (Cellgro, Mediatech, Herndon, VA) supplemented with $10 \%$ fetal bovine serum, $1 \%$ penicillin, and $1 \%$ L-glutamine. Cultures were incubated at $37{ }^{\circ} \mathrm{C}$ with 95:5\% mixture of air: $\mathrm{CO}_{2}$. Media was refreshed twice in week 1 and once during week 2 . Cells were trypsinized, plated on six-well plates, and treated with nPM $(10 \mu \mathrm{g} /$ $\mathrm{mL}, 24 \mathrm{~h}$ ) or LPS (100 ng/mL, $48 \mathrm{~h}$ for microarray, $24 \mathrm{~h}$ for TLR4 knockdown). The $10 \mu \mathrm{g} / \mathrm{mL}$ dose of $\mathrm{nPM}$ is based on published work demonstrating conditioned media from mixed glia treated with $10 \mu \mathrm{g} / \mathrm{mL} \mathrm{nPM} \mathrm{re-}$ duced inhibited neurite outgrowth and reduced the number of neurites [18].

\section{RNA}

Total cell RNA was isolated by TRIzol; cDNA was reverse transcribed (Promega) and analyzed on Affymetrix Rat Whole Genome 230.2 array. For individual gene verification, q-PCR was done with Taq Master Mix (Biopioneer), with primers designed with Primer3 and verified by NCBI Primer-BLAST (Basic Local Alignment Search Tool). Data was quantified as $\triangle \triangle \mathrm{CT}$ and normalized to GAPDH.

\section{Microarray analysis}

For nPM microarray, RNA-cDNA was prepared from $N=4$ treated and $N=4$ controls. For LPS cultures, we compared five treated versus four control cultures. Microarray was verified by q-PCR, with $N=14$ per group.

\section{Normalization}

Raw Affymetrix data were normalized by the Robust Multi-array Averaging $\mathrm{R}$ algorithm [44-46]. The output is then transformed to $\log _{2}$. LPS and nPM microarrays were independently normalized to controls within each individual experiment. These datasets are available as raw data files, given in Additional file 1.

\section{Significance analysis of microarrays (SAM)}

Normalized microarray data were analyzed for fold change by SAM, to assess differential expression associated with nPM and/or LPS exposure relative to controls. The input into SAM was an individual $\log _{2}$ fold change score for each microarray probe, with significance calculated using permutation tests (100 permutations) and presented as $q$-values to account for false discovery rate, with an FDR threshold at $1 \%(q<0.01)$.

\section{Weighted gene co-expression network analysis (WGCNA)}

Gene expression networks were identified using the WGCNA package in $\mathrm{R}$ [47]. Adjacency matrices for $\mathrm{nPM}$ and LPS were generated by first calculating biweight midcorrelations of gene expression for each gene pair. To construct weighted gene networks, these measures of co-expression (correlation coefficients) are raised to a power of $\beta$-the soft-thresholding power. This value is chosen by analyzing scale-free topology. More information on selecting a $\beta$ value can be found in work by Zhang and Horvath [48]. For this analysis we used a soft-thresholding power of 6. Adjacency for each gene pair was then defined using topological overlap matrices (TOMs). TOM incorporates higher-order connections by taking into account the number of "neighbors", or connections, that a pair of genes share [49]. Individual TOMs were estimated for both nPM and LPS. A consensus topological overlap (across nPM and LPS) was calculated using the component-wise (parallel) minimum of the individual TOMs. TOMs were then converted to dissimilarity matrices by subtracting from 1 . Modules were then defined by employing hierarchical clustering with TOMs as input with the following WGCNA parameters: unsigned network, minimum module size of 30, and medium sensitivity (deepSplit = 2). Hierarchical clustering assigns each gene to a specific module (denoted by different colors), which represent networks of highly interconnected genes.

Following module assignment, eigengenes were estimated for each module. The eigengene is a single quantitative value for a module, which represents its overall gene score, based on levels of messenger RNA (mRNA) for all genes assigned to that module. The use of eigengenes enables dimension reduction-instead of comparing gene expression between exposure and controls for thousands of genes, comparisons of higher-order measures of gene expression between exposure and controls can be carried out for less than 100 modules. We then screened for hub genes (genes that are highly connected within a given module). Although the hierarchical clustering assigns each gene to one module, module membership can be defined by calculating eigengene-based connectivity (kME) for each gene-by-module pair as the correlation between expression levels of a gene and the eigengene (quantitative score) for a module. kME was calculated in each set (nPM and LPS), then consensus kME scores were generated as meta-analytic scores by Stouffer's method. Based on $\mathrm{kME}$, hubs for each module were defined as the genes with the highest connectivity ( $\mathrm{kME} \geq 0.80$ ).

\section{Pathway analysis}

Pathway enrichment analysis by Kyoto Encyclopedia of Genes and Genomes (KEGG) (www.genome.jp/kegg/) and Gene Ontology (GO; Gene Ontology Consortium, geneontology.org) used two gene sets as inputs-those with differential expression for both the nPM and LPS treatment (SAM results), and those identified as hub genes in modules enriched by both nPM and LPS 
(WGCNA results). Whereas GO was utilized in SAM to determine only the most enriched responses, GO is utilized here to describe the composition of the module and therefore uses relaxed stringency. Increased and decreased transcripts were considered independently [50]. Pathway figures were generated using Cytoscape with the ClueGo plugin [51], with enriched processes depicted as nodes, and networks, which are groups of connected nodes.

Genes significant by SAM from each dataset, and shared hub genes from modules enriched by both treatments were analyzed for enriched transcription factor targets (TFTs) using WEB-based Gene Set Analysis Toolkit (WEB-GESTALT); cutoff at $p<0.01$. Because TFT analysis makes corrections for false positives, TFT analysis has more power in connected networks (WGCNA modules) versus broad gene lists (SAM results) and can therefore detect greater TFT enrichment in a subset versus complete gene lists.

\section{TLR4 siRNA cultures}

Glia were transfected with lipofectamine $(10 \mu \mathrm{L} /$ well media) and TLR4 siRNA (Thermo Fisher Scientific, siRNA ID 198667), or negative control siRNA (Thermo Fisher Scientific, AM4611), combined with Opti-MEM media and added to culture media. For control cultures, only Opti-MEM media was added to culture media. After $48 \mathrm{~h}$, cells were treated with either nPM $(10 \mu \mathrm{g} /$ $\mathrm{mL}, 24 \mathrm{~h})$ or LPS (100 ng/mL, $24 \mathrm{~h})$, and harvested for RNA (TRIzol) and protein (RIPA buffer).

Scrambled RNA induced JNK1/2 (no change by nPM, $1.6 \times$ by scrambled RNA) and STAT $1(4.7 \times$ by $\mathrm{nPM}, 7.4 \times$ by scrambled RNA), with no effect on other genes queried. nPM effects were unchanged by scrambled RNA.

\section{Inflammatory proteins}

Protein concentration was analyzed by the V-PLEX Proinflammatory Panel 2 immunoassay (K15059D-1, Mesoscale Diagnostics, Rockville, MD).

\section{Statistical analysis}

Ordinary one-way analysis of variance test was used, with Tukey's posttest to correct for multiple comparisons. All analysis used Graphpad Prism 6.

\section{Heatmap}

Hierarchical clustering and heatmap generation were performed in MatLab (Version R2014b) to identify the relation of gene expression changes among different groups of this study. Genes were clustered by Pearson correlation coefficients.

\section{Results}

Strategy

Mixed glial acute responses to nPM and LPS were analyzed by whole genome microarray and processed in tandem by significance analysis of microarrays (SAM), and by weighted gene co-expression network analysis (WGCNA) (Fig. 1). SAM identified responses in individual RNAs, by fold change, to $\mathrm{nPM}$ or LPS. WGCNA determined shared RNA responses between nPM and LPS treatments, defined as modules for groups of RNAs with correlated expression. The results from SAM and WGCNA were then analyzed for enriched biological processes, by Gene Ontology (GO), and for transcription factor targets (TFTs).

Guided by results from microarray analysis, we investigated TLR4 involvement in nPM response by TLR4 knockdown in vitro, and investigated TLR4 activation in the hippocampus following chronic in vivo exposure.

\section{Significance analysis of microarrays (SAM)}

The nPM treatment altered 1996 RNAs, with 920 increased and 1076 decreased (Venn diagrams, Fig. 2a-c; $q<0.1$ ). This analysis only considered RNA changes with

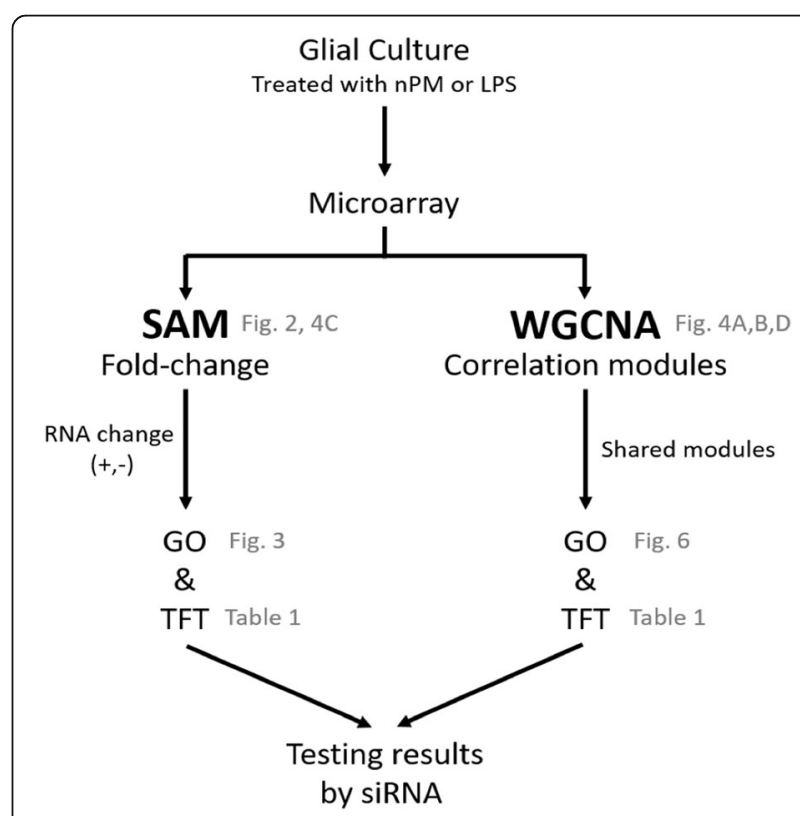

Fig. 1 Flowchart of analysis. RNA responses of mixed glial cultures to nPM or LPS were analyzed by whole genome microarray for fold change by significance analysis of microarrays (SAM), and for shared RNA responses by weighted gene co-expression network analysis (WGCNA), given as correlation modules. Correlation modules are the clusters of correlated genes. The results from SAM and WGCNA were then analyzed for biological processes using the Gene Ontology (GO) database, and transcription factor targets (TFTs). GO output is given as nodes, which are enriched biological processes, and as networks, which are groups of connected nodes. Responding RNAs that met the criteria for fold change were analyzed for GO and TFT enrichment. For WGCNA, only modules of shared responses between nPM and LPS were examined 


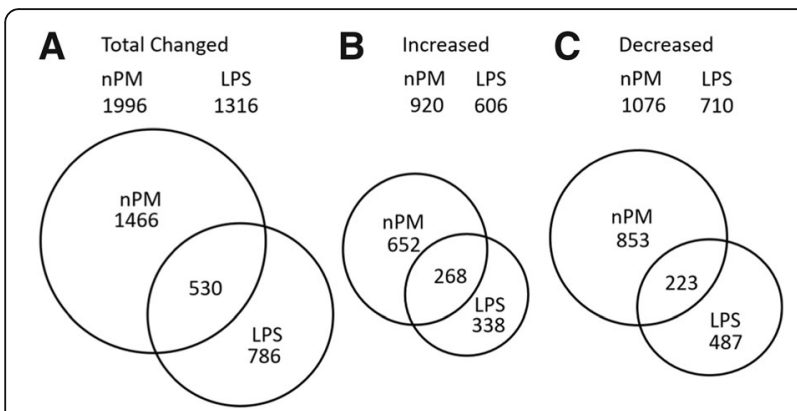

Fig. 2 Venn diagram of RNA by significance analysis of microarrays (SAM). Areas of each circle are in proportion to gene numbers. a Total RNAs altered by either treatment. $\mathbf{b}$ Increased RNAs by either treatment. c Decreased RNAs by either treatment $q$-values of 0.01 and with minimum changes of $1.5 \times$ for increases and of $0.7 \times$ for decreases. LPS induced 1316 RNA responses, with 606 increased and 710 decreased. nPM altered 50\% more RNAs than LPS, for both the increased and decreased.

Among the RNA responders to LPS and nPM, 530 were shared: 268 increased in both; 223 decreased in both (Fig. 2a-c; $q<0.1$ ). A subset of 39 RNAs had divergent directions of response to nPM and LPS, with $80 \%$ increased by nPM. Divergent responses were analyzed by GO ("SAM biological processes analysis by Gene Ontology (GO)").

\section{Verification by $q-P C R$}

Eight TNF $\alpha$-associated RNA level changes detected by microarray were confirmed by q-PCR: five increased (Jak2, STAT1, TNF $\alpha$, TNFRSF9, and TRAFD1) and three non-changers (Fos, TRAF3ip, and TRAF6) (Additional file 2: Figure S1).

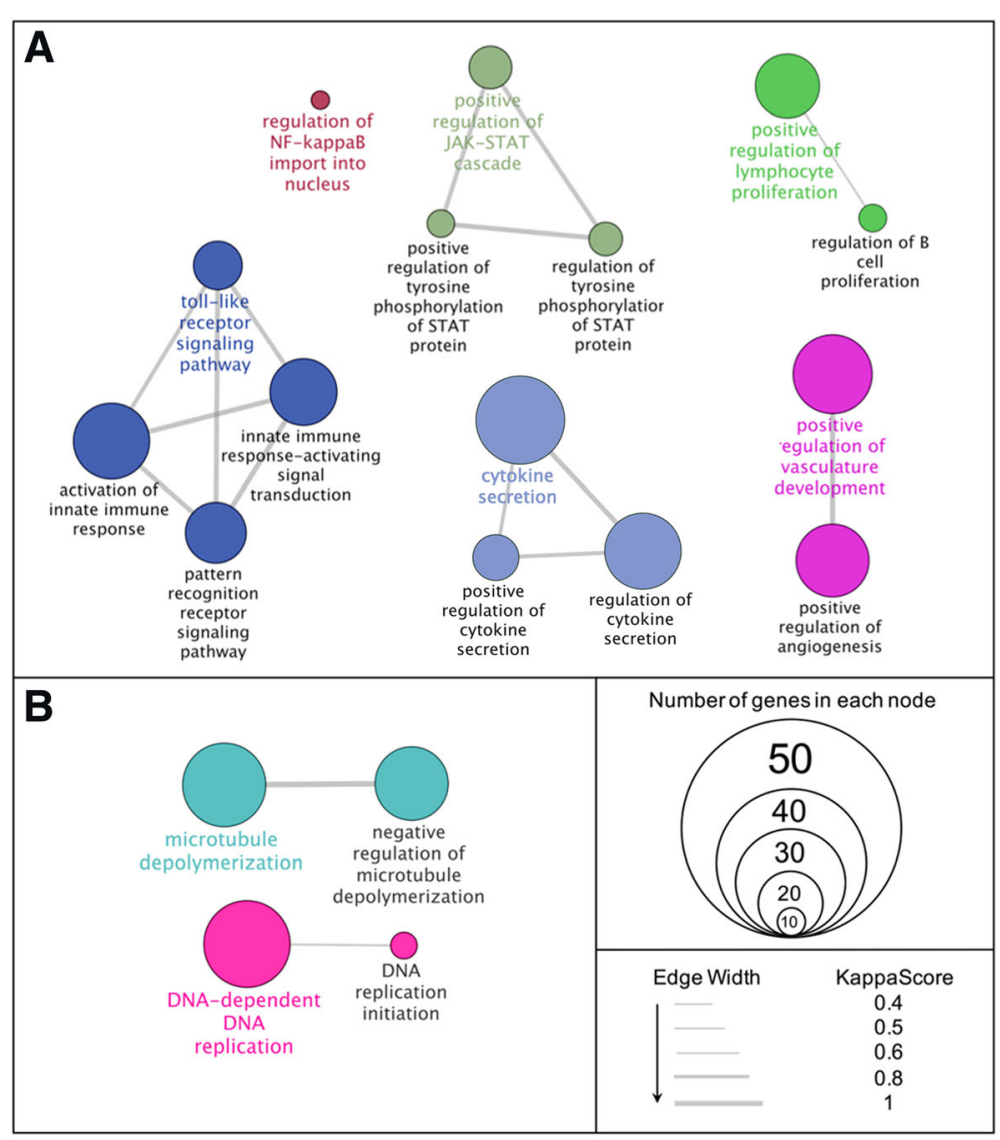

Fig. 3 GO processes for nPM responses, analyzed by significance analysis of microarrays (SAM). a nPM-increased RNAs: (920), clustered into networks. Note the single node of NF-KB regulation, and TLR signaling pathway network. The cellular migratory network was condensed from 13 nodes to 5. Migratory pathways for T cells and other leukocytes identified by GO analysis are not depicted. b nPM-decreased RNAs (1076): Although 17\% more RNAs were decreased than the increases, there were fewer enriched pathways. $p<0.00001$. Colors denote different networks. Nodes with two colors belong to both networks. Each network has one highlighted node (colored text, chosen by experimenter) that best represents network function. The circle size represents the number of genes enriched in the node. The width of connecting lines represents the strength of connectivity between nodes, as measured by kappa score 
SAM biological processes analysis by Gene Ontology (GO) The top enriched biological processes (20\% minimum enrichment) by nPM or LPS were determined from GO.

$n P M$ responses: Increased RNAs were associated with 28 GO processes (depicted as nodes, Fig. 3a), including genes of a priori interest NF- $\mathrm{KB}$ and TLR4 ("Background"). "Regulation of NF- $\mathrm{kB}$ import into nucleus" was represented as one node. Multiple node networks included "Toll-like receptor signaling pathway" (four nodes), "cytokine secretion" (three nodes), and "positive regulation of JAK-STAT cascade" (three nodes). Not depicted in Fig. 3a are "cell migration" nodes, which were enriched for migratory processes of neutrophils, granulocytes, and T cells. These were excluded because of overlap in "migratory" genes between cell types. Decreased RNAs from nPM treatment had two GO networks, each with two nodes: "DNA-dependent DNA replication" and "microtubule depolymerization" (Fig. 3b).

KEGG pathway analysis corroborated the main GO findings: increased RNAs for enrichment in NF- $k B$, TLR signaling, and cytokine response; decreased RNAs, for enrichment in DNA replication (not shown).

LPS responses: Increased RNAs yielded 18 enriched nodes, including "response to tumor necrosis factor", "IkappaB kinase/NF-kappaB signaling", "response to oxidative stress", "reactive oxygen species metabolic process", "chronic inflammatory response", "response to interferon gamma", "nitric oxide biosynthetic process", and "response to cytokine" (Additional file 2: Figure S1). Unlike nPM GO, LPS had enriched processes for "antigen processing and presentation of peptide antigen" and "reactive nitrogen species metabolic processes", among others. Decreased RNAs were enriched for "regulation of protein serine/threonine kinase activity" and "response to wounding" (not shown).

Data from prior microarray analysis of LPS-treated BV-2 microglial cells $[34,35]$ and primary cultured microglia [36] were also analyzed for GO processes. These datasets showed LPS responses of NF-kB, IFN-y, oxidative stress, and cytokine pathways, corresponding to our results.

Divergence between nPM and LPS: For the 39 RNAs with divergent responses by SAM, identified above ("Significance analysis of microarrays (SAM)" section), one third $(15 / 39)$ were in the "response to chemical stimulus".

\section{Weighted gene co-expression network analysis (WGCNA)}

Joint modules of response to nPM and LPS were identified by WGCNA. The WGCNA for nPM and LPS responses gave 45 gene modules, shown as a cluster dendrogram (Fig. 4a). Of these 45 modules (Fig. 4b), 38 were associated with nPM, 4 modules associated with LPS (Fig. 4c), and 2 modules enriched in both exposures (Fig. 4c, right column). These shared modules were the blue module, composed of increased RNAs (total 2042), and turquoise module, decreased RNAs (total 2612). The relationship of the 45 modules with fold change, as derived by SAM, is seen in Fig. $4 \mathrm{~d}$.
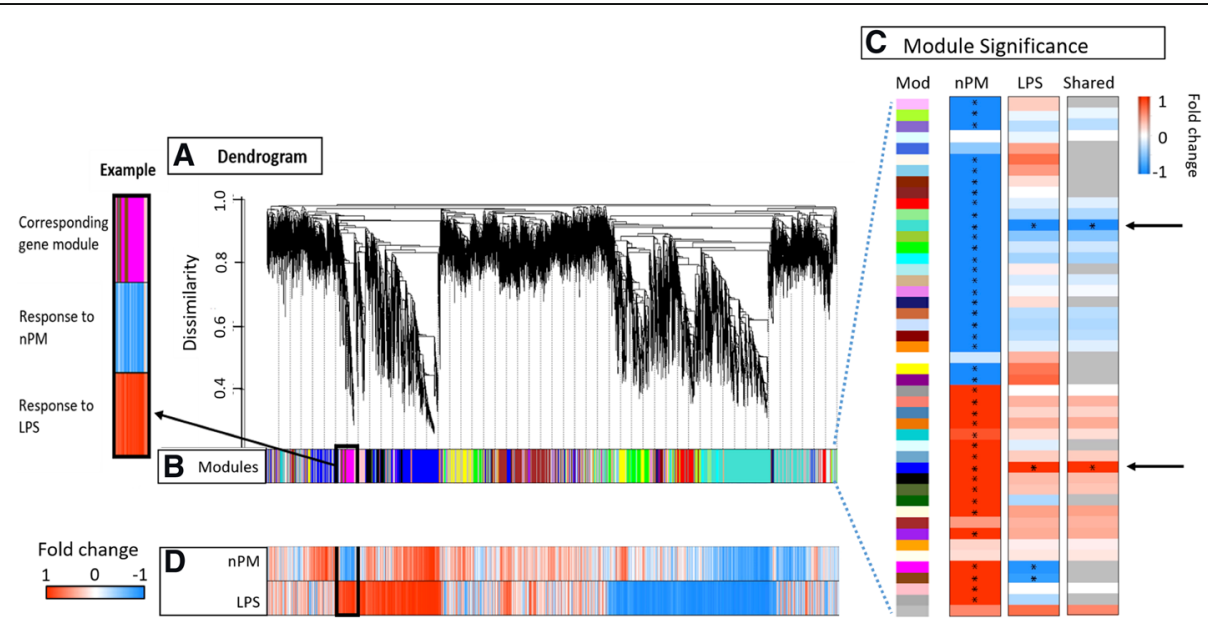

Fig. 4 Weighted gene network co-expression analysis (WGCNA) of nPM and LPS responses, grouped as modules. a Dendrogram using hierarchical clustering to group genes by lowest values generated by a dissimilarity matrix. b Modules, color labeled for each gene (arbitrary colors), with modules placed by highest similarity between gene clusters. 45 modules were generated by WGCNA. c Statistical significance of each weighted gene co-expression network analysis (WGCNA) module, for nPM, LPS, and shared responses. Module colors from Fig. 4b are in the leftmost column (Mod). Modules from Fig. 3 with significant change $(p<0.01)$ are denoted by *. Of these 45 modules, 38 were enriched in the nPM subset, 4 in LPS subset, and 2 in the shared subset. Shared modules, which will be further analyzed for pathway enrichment, are marked by arrows. Scale bar is correlation coefficients between module eigengene and treatment condition. $\mathbf{d}$ Normalized fold change of RNA for each gene from nPM and LPS responses, respectively: red, increases; blue, decreases. Upper left, expanded section of $\mathbf{b}$ and $\mathbf{c}$ 
In the blue module (increased RNAs), nPM responders had twofold more hub genes (1196/2042) than LPS responders (558/2042). For the shared responses of nPM and LPS, hub genes were $25 \%$ (497/2042). The turquoise module (decreased RNAs) with 530 shared hub genes had 2.7-fold more hub genes for nPM (1842/2612) than for LPS (681/2612). The hub genes of the blue and turquoise modules were highly correlated by kME and by fold change (biweight mid-correlation +0.44 for $\mathrm{nPM}$, blue; -0.24 for $\mathrm{nPM}$, turquoise).

\section{WGCNA process analysis by Gene Ontology (GO)}

The hub genes of the two shared WGCNA modules, blue and turquoise, were analyzed by GO (Fig. 5a, b, respectively).

The shared hub genes for both nPM and LPS treatment in the blue module (increased RNAs) enriched similar biological processes as the SAM analysis for nPM treatment (Fig. 3a): "I-kappaB kinase/NF-kappaB signaling", "TLR signaling pathway", "JAK-STAT cascade", "cytokine secretion", and "response to LPS", among other processes (Fig. 5a). The shared nodes include genes composing the intracellular TLR4 signaling pathway, components of NF$\kappa \mathrm{B}$, and downstream inflammatory cytokines like TNF $\alpha$, IL- $1 \alpha$, and IL-1 $\beta$. All a priori genes of interest ("Background") were in the blue (increased) module.

The shared hub genes in both nPM and LPS treatment, of turquoise module (decreased RNAs), were enriched for "DNA replication" (also in Fig. 3b), "regulation of dendritic spine development", "chromatin assembly or disassembly", "positive regulation of purine nucleotide biosynthetic process", and "cellular biogenic amine metabolic process" (Fig. 5b).

\section{Transcription factor DNA binding target (TFT)}

Responding RNAs were analyzed for TFTs of their respective genes (Table 1). For nPM, by SAM, there was no enrichment of any TFT. Response to nPM, analyzed by WGCNA, was enriched for BACH1 (regulator of Nrf2 and phase-2 detoxification responses), interferon

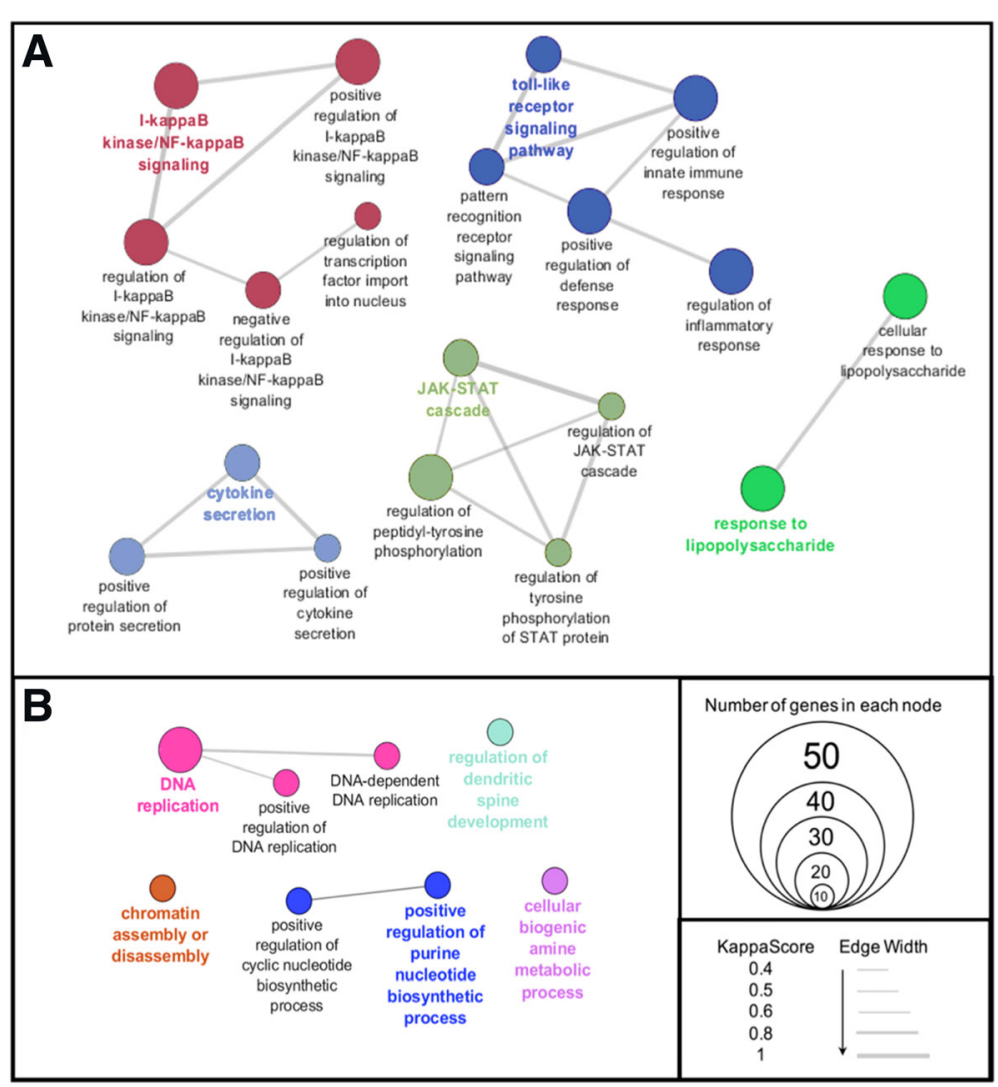

Fig. 5 Composition and biological relevance of the two modules enriched by both nPM and LPS. Blue (a) and turquoise (b) modules, by GO. Shown above are some select GO processes of interest that are enriched in the two modules. Notably, WGCNA composed the blue module of all increased RNAs, while the turquoise module was decreased RNAs. a Many of the pathways observed in the more stringent GO analysis of SAM analysis of nPM are represented in the shared blue module. These include the TLR4 signaling pathway, NF-KB pathway, and inflammatory cytokines. b Some similar pathways to decreased RNAs by SAM are observed in the turquoise module, including DNA replication. Nodes with highlighted texted were chosen as the node that best represents the network; node colors distinguish between networks. Nodes with two colors belong to both networks. The circle size represents the number of genes enriched in the node. The width of connecting lines represents the strength of connectivity between nodes 
Table 1 Transcription factor target (TFT) analysis

\begin{tabular}{|c|c|c|c|c|c|c|}
\hline \multirow{2}{*}{$\begin{array}{l}\text { Transcription } \\
\text { factor }\end{array}$} & \multicolumn{2}{|l|}{$n P M$} & \multicolumn{2}{|l|}{ LPS } & \multicolumn{2}{|c|}{ Shared } \\
\hline & SAM & WGCNA & SAM & WGCNA & SAM & WGCNA \\
\hline AP-1 & - & - & 1 & - & - & - \\
\hline $\mathrm{BACH} 1$ & - & 1 & - & - & - & - \\
\hline IPF1 & - & 1 & - & - & - & - \\
\hline IRFs & - & 3 & 6 & 4 & 6 & 4 \\
\hline NFAT & - & 1 & 1 & 1 & - & 1 \\
\hline$N F-k B$ & - & - & 2 & 2 & 5 & 2 \\
\hline NF1 & - & 1 & - & - & - & - \\
\hline SRF & - & - & - & - & 2 & 1 \\
\hline STAT1 & - & - & - & 1 & 1 & - \\
\hline
\end{tabular}

Numbers represent the total of different TFT binding sequences enriched for each dataset queried. Only the blue and turquoise modules (Fig. 4) were used for WGCNA

Abbreviations: AP-1 activator protein 1, BACH1 BT3B and CNC homology 1, IPF1 insulin promoter factor $1, I R F$ interferon regulatory factor, NFAT nuclear factor of activated T cells, NF- $K B$ nuclear factor kappa-light-chain-enhancer of activated $B$ cells, NF1 neurofibromin 1, SAM significance analysis of microarrays, SRF serum response factor, STAT1 signal transducers and activator 1

regulatory factors (IRFs), and other TFTs (Table 1). LPS showed 10 TFTs by SAM, and 8 by WGCNA, with multiple TFTs for interferon regulatory factors (IRFs) by both analyses.

The shared responses showed the largest enrichment of TFTs, with six TFTs for IRFs and five for NF- $\mathrm{B}$ from the RNAs shared by SAM. Analysis by SAM had four and two TFTs for IRF and NF- $\mathrm{kB}$, respectively.

Both IRFs and NF- $\kappa$ B are controlled by intracellular processes following TLR4 activation, suggesting that TLR4 is a mediator of glial responses to nPM and LPS.

\section{TLR4 siRNA experimental manipulations}

We verified that TLR4 mRNA was increased $2 \times$ by nPM, with no change by LPS (Fig. 6a), whereas TLR4 protein was not altered by nPM or LPS (Fig. 6b). The lack of TLR4 protein induction corroborates findings that LPS, despite activating TLR4, does not increase TLR4 protein by $24 \mathrm{~h}$ post treatment [52]. The bioinformatics findings were validated by siRNA manipulation of TLR4.

\section{TLR4 knockdown}

The siRNA knockdown of TLR4 was confirmed for protein and mRNA. TLR4-siRNA treatment lowered RNA similarly in controls (65\%) and nPM (80\%) (Fig. 6a). siRNA for TLR4 lowered protein levels by $60 \%$ in all groups (Fig. 6b). Scrambled siRNA treatments for TLR4 did not differ from controls (Fig. 6a).

\section{Inflammatory proteins}

$\mathrm{nPM}$ treatment increased protein concentration for six of seven investigated proteins (Fig. 7). TLR4 siRNA

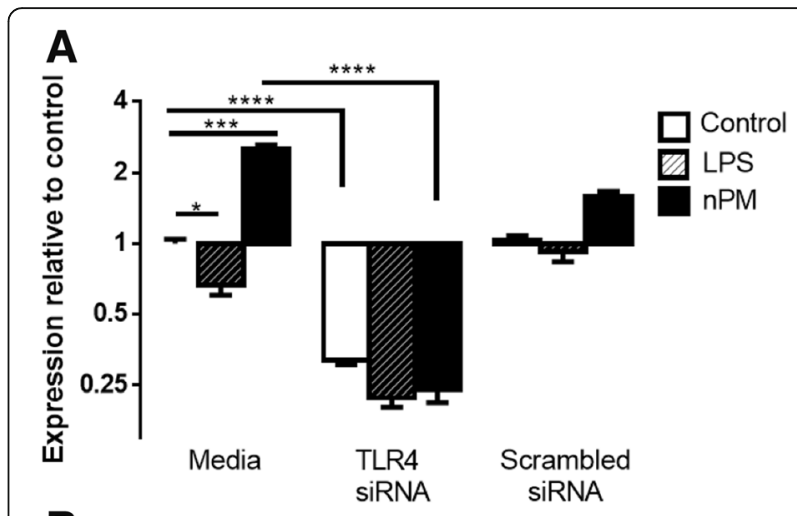

B

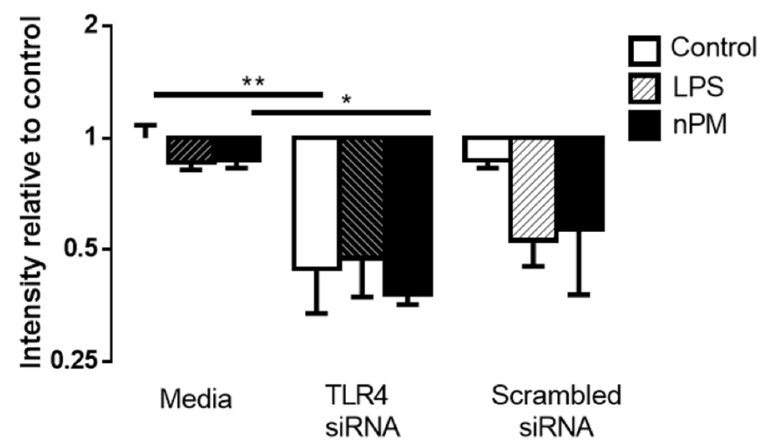

Fig. 6 TLR4 response in mixed glia. Mixed glia: TLR4 siRNA treatment lowered TLR4 mRNA and protein, and attenuated nPM induction of TLR4 mRNA. Media groups are non-transfected. a TLR4 mRNA, but not protein, was induced by nPM. TLR4 siRNA decreased TLR4 mRNA levels by $90 \%$ in nPM (ANOVA, $p<0.0001$ ) and $70 \%$ in control groups ( $p<0.0001)$. LPS treatment reduced TLR4 mRNA $(p<0.05)$. b TLR4 protein was not changed by nPM or LPS. TLR4 siRNA reduced protein levels by ca. $60 \%$ in all groups (ANOVA, $p<0.05$ )

reduced induction by $\mathrm{nPM}$ for TNF $\alpha$, IL-1 $\beta$, IL-6, and KC. TLR4 siRNA had no effect on nPM response for IL5, IL-4, and IFN-y.

The 30-fold increase of TNF $\alpha$ protein by $\mathrm{nPM}$ was blocked by siRNA (-80\%) (Fig. 7a). TNF $\alpha$ mRNA was also increased eightfold by nPM, and blocked by siRNA $(-80 \%)$ (see below). IL-1 $\beta$ protein increased by nPM $(5.5 \times)$ (Fig. 7b). siRNA treatment induced IL-1 $\beta(2.3 \times)$, with a modest further induction by $\mathrm{nPM}(1.3 \times)$ (Fig. 7b). IL- 6 protein increased $80 \times$ by nPM, with reduced induction by $\mathrm{nPM}$ in siRNA cultures $(3.4 \times)$ (Fig. 7c). nPM treatment increased $\mathrm{KC} 142 \times$, with reduced induction by $n P M$ in siRNA cultures $(5.8 \times)$ (Fig. $7 d)$.

\section{TLR4 pathways}

nPM activated the MyD88-dependent TLR4 pathway, but did not activate the MyD88-independent endocytosis pathway. MyD88 was increased by both LPS and nPM (1.3× for both), and blocked by siRNA-TLR4 (Fig. 8a). TRAF6, which is downstream of MyD88-dependent TLR4 activation, did not respond to nPM or LPS (not shown). TAK1, a downstream effector of TRAF6, was also unchanged by nPM or 

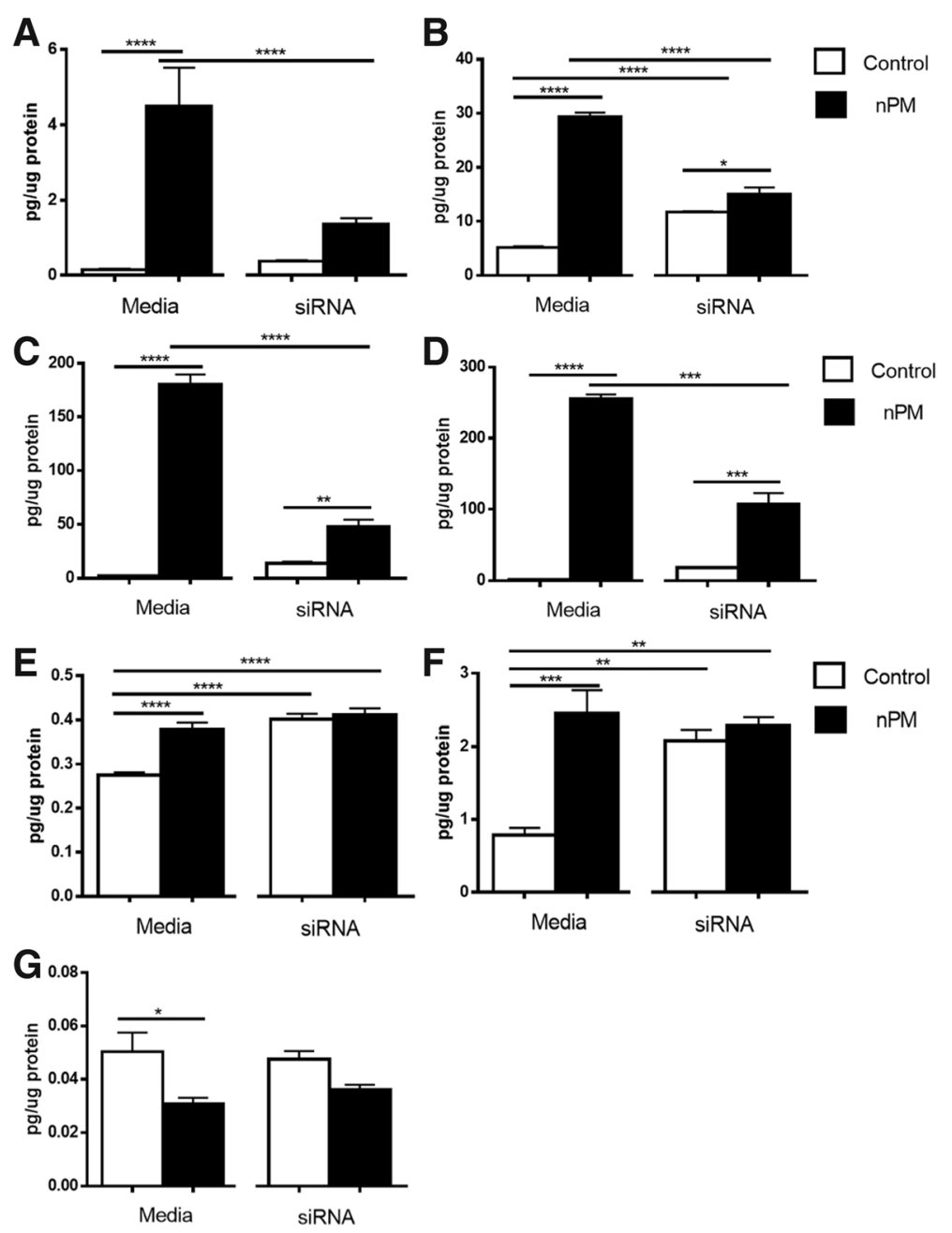

Fig. 7 Inflammatory protein panel. Mixed glia: induction of inflammatory cytokines by nPM, with attenuation by TLR4 siRNA. Media groups are non-transfected cultures. a TNFa was increased by nPM treatment $(p<0.001)$. siRNA treatment reduced TNFa protein response to nPM $(p<0.0001)$. TNFa protein in siRNA cultures treated with nPM did not differ from controls. $\mathbf{b} \| \mathrm{L}-1 \beta$ was increased by $\mathrm{nPM}(p<0.001)$. IL-1 $\beta$ induced by $n P M$ was attenuated by TLR4 siRNA $(p<0.001)$. c nPM increased IL- 6 protein $(p<0.0001)$. TLR4 siRNA reduced nPM IL-6 induction versus non-transfected cultures $(p<0.0001)$. $\mathbf{d ~ K C}$ protein was increased by nPM in both non-transfected cultures $(p<0.0001)$ and TLR4 siRNA $(p<0.001)$, with attenuated induction in siRNA cultures. e IFN-y was increased by nPM $(p<0.0001)$ and by TLR4 siRNA $(p<0.0001)$. $\mathbf{f} \|-5$ was increased by nPM $(p<0.001)$, and by siRNA $(p<0.01)$, with no further increase by nPM. $\mathbf{g} \mid \mathrm{LL}-4$ was decreased by $\mathrm{nPM}(p<0.05)$

LPS (not shown). TRAFD1, which shows negative feedback on TRAF6, was increased by nPM and LPS $(2 \times$ and $3 \times$, respectively), blocked by TLR4 siRNA (Fig. $8 \mathrm{~b})$.

$\mathrm{NF}-\mathrm{kB}$ was increased by $\mathrm{nPM}(2 \times)$, with induction blocked by TLR4 siRNA (Fig. 8c). Mentioned above ("Inflammatory proteins"), TNF $\alpha$ was increased $8 \times$ by nPM, and blocked by TLR4 siRNA (-80\%) (Fig. 8d). TNFR1 mRNA did not respond to nPM or LPS (not shown).

In the JAK/STAT pathway, JAK2 was activated by nPM and LPS (6.1× and 3.7×, respectively), with siRNA blockade (Fig. 8e). STAT1 mRNA was increased by nPM $(4.8 \times)$ and by LPS (9.1×), and also siRNA blocked (Fig. 8f).

TRIF (Toll/IL-1 receptor domain-containing adaptor protein-inducing IFN- $\beta$ ), of the MyD88-independent endocytosis pathway, was decreased by LPS $(0.72 \times, p$ $<.05)$ and did not respond to nPM (not shown). IFN$\beta$ did not respond to nPM or LPS (not shown). This further confirms the absence of endotoxin activity in our nPM, because the "endocytosis pathway" is a known endotoxin-specific TLR4 response.

Figure 9 summarizes these responses ("Inflammatory proteins" and "TLR4 pathways") by pathway.

\section{Comparative expression}

A heatmap of all genes queried by q-PCR in the TLR4 pathway (Fig. 9) shows clusters by genes on the $y$-axis, and treatment groups on the $x$-axis (Fig. 10). 

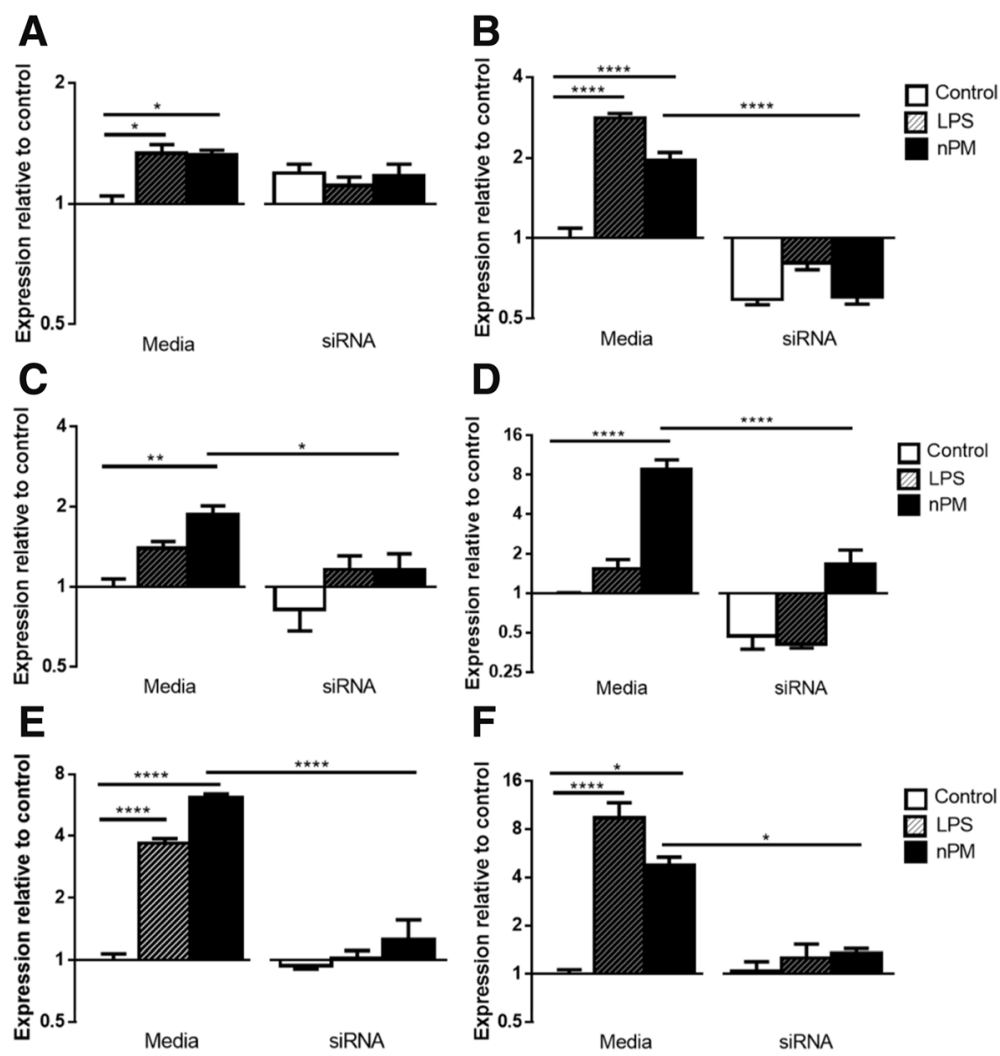

Fig. 8 TLR4 pathway activation in mixed glia. Mixed glia: nPM increased mRNAs in the MyD88-dependent TLR4 signaling pathway. Media groups are non-transfected cultures. All values are given as $\log _{2}$ fold change. a MyD88 was increased by both nPM and LPS $(p<0.05)$, with no change observed in TLR4 siRNA-treated cultures. b TRAFD1 mRNA was increased by nPM treatment $(p<0.0001)$ and by LPS treatment $(p<0.0001)$, and rescued by siRNA treatment $(p<0.0001)$. c NF-KB mRNA was increased by nPM treatment $(p<0.01)$, and rescued by siRNA treatment $(p<0.05)$. $\mathbf{d}$ TNFa mRNA was induced by nPM treatment $(p<0.0001)$. siRNA treatment reduced nPM induction of TNFa mRNA $(p<0.0001)$. e JAK2 mRNA was increased by nPM and LPS treatment $(p<0.0001)$, and rescued by siRNA treatment $(p<0.0001)$. f STAT1 mRNA was increased by nPM and LPS treatment $(p<0.01$ and $p<0.0001$, respectively), and rescued by siRNA treatment $(p<0.05)$

Treatment clustering ( $x$-axis): the non-transfected cultures, the control group shows the least similarity to the nPM and LPS groups. The clustering of three TLR4 siRNA groups suggests similar responses. Importantly, on the heat map, the TLR4 siRNA-treated cultures are in the adjacent column to the control group, indicating the siRNA treatment returned RNA to control levels. Gene clustering ( $y$-axis): NF- $\mathrm{KB}$, TLR4, and JAK2, cluster with TLR4.

\section{In vivo $\mathrm{nPM}$ exposure}

To investigate TLR4 involvement in vivo, we examined TLR4-associated responses in the hippocampus of adult mice chronically exposed to nPM for $150 \mathrm{~h}$ over 10 weeks. TLR4 and MyD88 RNAs were increased by this nPM exposure (2.1× and $1.4 \times$, respectively) (Fig. 11a, b), while NF- $\mathrm{KB}$ and TRAF6 were decreased $(0.8 \times$ and $0.75 \times$, respectively) (Fig. 11c, d). Increases were observed for TNF $\alpha(10 \times)$ (Fig. 11e) and TNFR2 (1.6x) (Fig. 11f). There was no response of TNFR1, c-Fos, or c-Jun (not shown).

\section{Discussion}

This is the first comprehensive expression analysis of rodent in vitro glial responses to TRAP particulate matter, which shows broad activation of immune and stress pathways in response to nPM, with 2000 transcripts responding. Guided by the expression analysis, we then demonstrated TLR4 knockdown attenuated a subset of inflammatory response to nPM. Finally, we showed that TLR4 and associated TLR4 pathway RNAs were altered in the hippocampus following in vivo $\mathrm{nPM}$ exposure.

This is also the first direct comparison of LPS and air pollution PM for gene expression responses. WGCNA in conjunction with SAM was used to show the extensive overlap of inflammatory responses between nPM and LPS. About $25 \%$ of the RNAs responding to nPM were shared with LPS responses. The overlap was enriched for inflammatory responses like TLR4, NF-kB, TNF $\alpha$, and multiple interleukins. Shared responses to $\mathrm{nPM}$ and LPS were also enriched in transcription factor targets (TFTs) for NF- $\mathrm{kB}$ and IRFs. These findings 


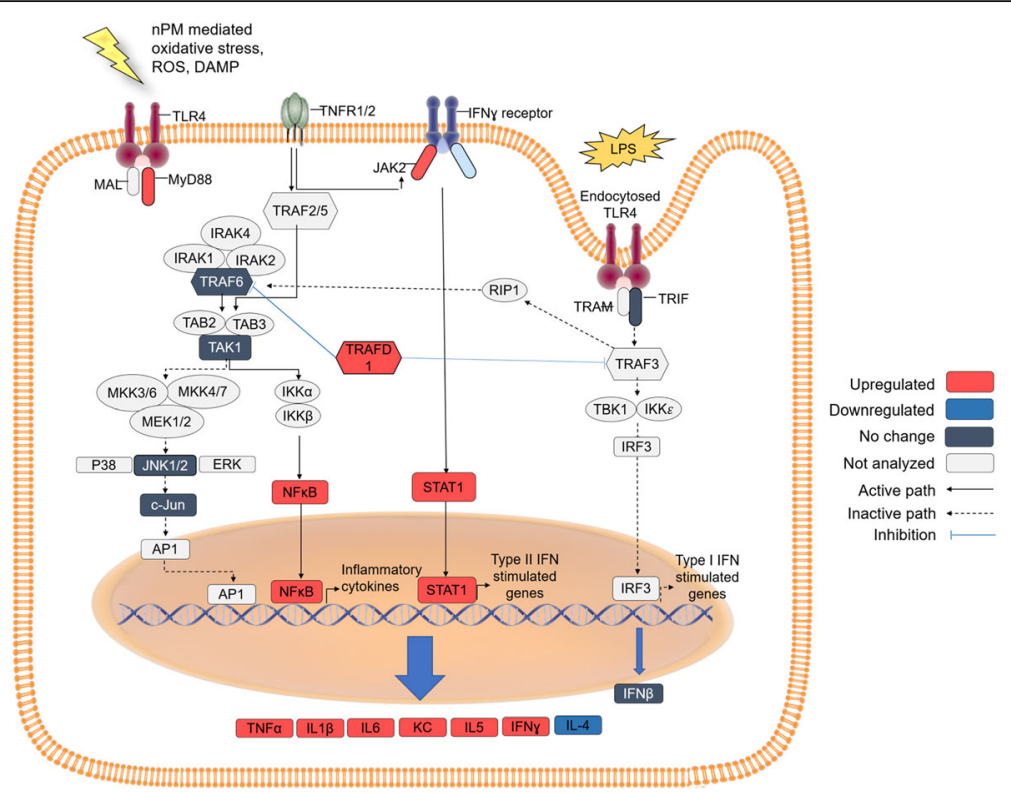

Fig. 9 Proposed pathway of TLR4 activation by nPM treatment. Red: TLR4-dependent increased mRNA or protein (cytokines). Dark blue: proteins or mRNA unresponsive to nPM. White: proposed intermediates, not examined. nPM activated MyD88-dependent pathways, increasing NF-KB mRNA and increasing downstream cytokine productions of NF-KB activation. JAK/STAT pathway was also activated by nPM with TLR4 dependence. LPS-mediated TLR4 receptor activation by endocytosis was not altered by nPM treatment

are consistent with the exacerbation of lung LPS inflammatory responses when combined with PM exposure $[53,54]$.

Importantly, the shared LPS and nPM responses were not due to endotoxin presence in these nPM samples. The negligible endotoxin activity of the nPM is consistent with

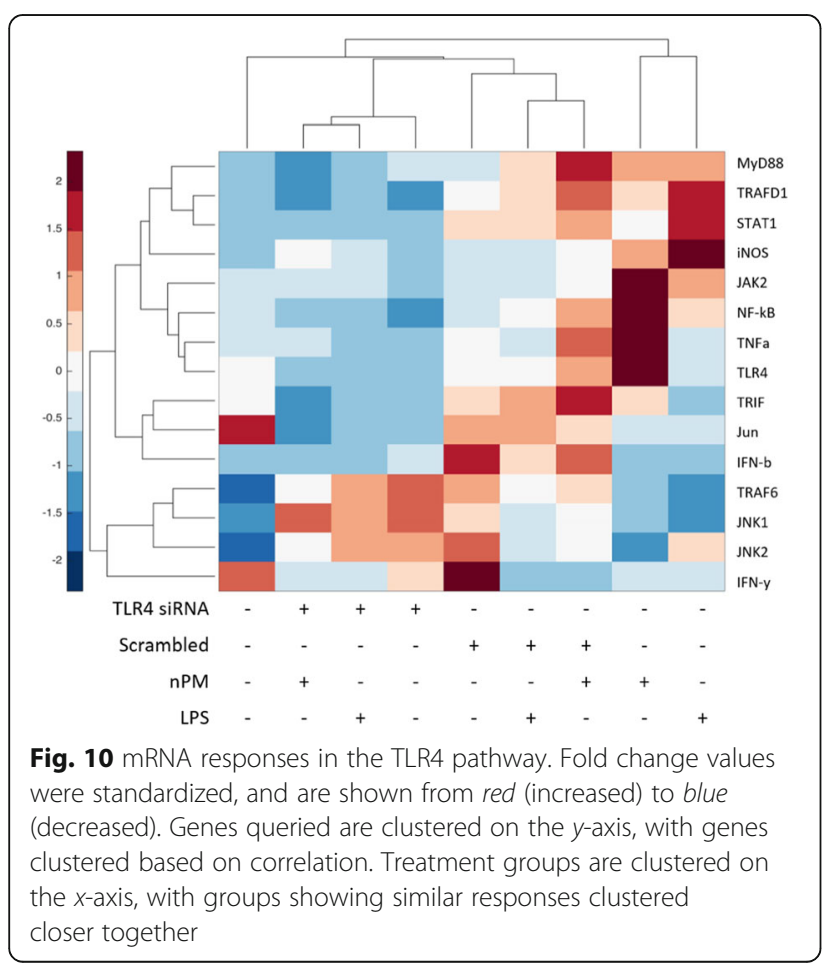

findings that the endotoxin contained within PM is mostly bound in large diameter particles (coarse PM) [33], which are excluded from collection of nPM. Physiologically, the coarse PM are mainly trapped in upper airways.

The $\mathrm{nPM}$ and LPS treatments differed 10-fold in the scale of responding RNA modules by WGCNA: nPM treatment enriched $85 \%$ (38/45) modules, while LPS enriched only $9 \%(4 / 45)$. This 10 -fold greater genomic response to nPM than LPS may be attributed to the greater chemical heterogeneity of the nPM, which includes transition metals, nitrate, sulfate, and water-soluble organic compounds [18].

Glial activation by air pollution exposure is characterized by cell-specific markers like GFAP (astrocytes) and Iba1 (microglia) [18, 23, 55], and by inflammatory cytokines like TNF $\alpha$ and IL-1 $\alpha$ [17, 18, 20, 21]. Our results with mixed glia corroborate the cytokine increases, and extend the responses to new signaling pathways including TLR4, NF- $\mathrm{KB}$, and JAK/STAT, as shown by WCGNA (blue module). The enrichment of transcription factors for NF-kB and IRFs by nPM treatment suggests the important role of TLR4 activation in glial responses to $\mathrm{nPM}$.

The TLR4-dependent glial responses to nPM were shown by TLR4 knockdown in vitro, which attenuated the nPM induction of TNF $\alpha$ and other cytokines. This is best visualized by the heatmap (Fig. 10). Nontransfected control and nPM or LPS-treated cultures were on opposite extremes of the heat map, indicating the least similarity of any conditions. Conversely, 


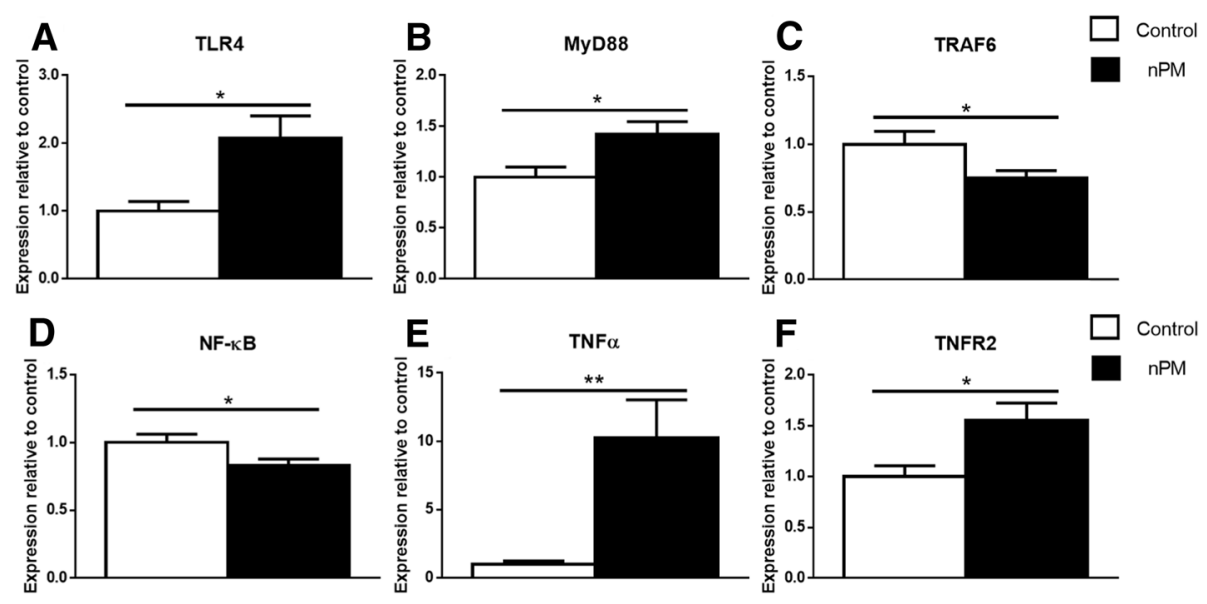

Fig. 11 Hippocampal responses to $n P M$ exposure in vivo. Mouse in vivo: Chronic nPM exposure induced components of the TLR4 pathway in hippocampus. mRNA responses by q-PCR are given, shown in relation to pathway (Fig. 7). $\mathbf{a}$ TLR4 mRNA was induced by nPM ( $p<0.05$ ). $\mathbf{b}$ MyD88 mRNA was increased by nPM ( $p<0.05)$. c TRAF6 mRNA was decreased by nPM $(p<0.0001)$. $\mathbf{d}$ NF-kB was decreased by nPM ( $p<0.05)$. e TNFa mRNA was increased by nPM $(p<0.01)$. f TNFR2 mRNA was increased by nPM $(p<0.05) . n=7$

TLR4 siRNA cultures treated with nPM or LPS were adjacent to control cultures, indicating highest similarity of any treatment groups. Though both nPM and LPS responses are TLR4 dependent, they function through divergent intracellular TLR4 signaling pathways. LPS activates TLR4 through both the TLR4 receptor endocytosis response to endotoxin, and the MyD88-dependent NF-kB inflammatory pathway. The $\mathrm{nPM}$ activated the NF- $\mathrm{kB}$ inflammatory response through MyD88-dependent signaling, but not the endocytosis pathway. NF- $\kappa B$ activation leads to increased TNF $\alpha$, IL$1 \beta$, and IL-6 (seen in "Inflammatory Proteins") [56]. In vivo exposure of mice to nPM induced hippocampal RNA changes for TLR4 components of MyD88-dependent NF$\kappa \mathrm{B}$ activation, and the TNF $\alpha$ pathway.

The activation of TLR4 with TNF $\alpha$ induction by nPM has implications for the neurodegenerative and cognitive impact of air pollution exposure (see "Background"). We hypothesize that TLR4 activation in glia is a mediator of neurite atrophy induced in young mice by air pollution PM, assessed as the area of silver-stained neuronal processes [8]. In co-cultures of mixed glia and neonatal neurons, nPM impairs neurite outgrowth, mainly via the TNF $\alpha$ secreted by nPM exposed mixed glia [27]. TLR4-knockout mice showed protection from airway inflammation [57], giving a rationale for considering neuroprotection by drugs that block TLR4. However, blocking TLR4 in humans, as a therapeutic approach must be considered cautiously, because attenuated TLR4 function, seen in human TLR4 SNP variants, increases the susceptibility to infection [58].

The direct translocation of nPM into the brain, via the nose, is consistent with the rapid translocation of radiolabeled carbon and manganese ultrafine PM into the brain from the olfactory neurons in the olfactory epithelium
$[25,26]$. Moreover, we recently showed rapid microglial activation in the olfactory epithelium following nPM exposure, with subsequent cortical neuroinflammation [23].

Other neurodegenerative conditions also involve TLR4 in glial and neuronal responses [59]. In cerebral ischemia/ reperfusion models for stroke injury, HSP70 binds to TLR4, activating MyD88-IRAK-TRAF6 and NF- $\mathrm{B}$ pathways, with downstream induction of TNF $\alpha$ and other cytokines [60, 61], as observed for nPM-LPS responses (Fig. 8). The synergies of cerebral ischemic damage with air pollution, observed clinically and in a rodent model [40], may now be understood as mediated by the nPMLPS TLR4 modules described here and the TLR4 role in cerebral ischemia [59].

The role of TLR4 may extend to pro-amyloidogenic air pollution associations [8, 62-64]. In transgenic mouse AD models, neurodegenerative changes were modulated with varying TLR4 expression $[65,66]$. Although no TLR variant has been validated as a risk factor for AD, TLR4-mediated monocyte responses showed individual variations with more than 1000 QTLs [67]. Notably, most of these QTLs involve genes associated with lysosome pathways, consistent with the endosomal associations of nPM-LPS in glial responses. These QTLs may be examined in future studies for SNPs that modify neurotoxic impact of air pollution. We anticipate a broad sharing of inflammatory gene variants that converge on TLR pathways in the neurodegenerative impact of air pollution that accelerates cognitive aging and increases dementia risk.

\section{Conclusions}

This in vitro evidence showed TLR4-dependent and independent glial responses to nPM. Knockdown of TLR4 
reduced $\mathrm{nPM}$ induction of numerous inflammatory cytokines, and attenuated activation of NF-kB and JAK/ STAT pathways. Chronic nPM exposure caused TLR4 activation in the hippocampus and increased TNF $\alpha$, which we hypothesize is a mediator of neurite atrophy in the hippocampus. These results further resolve the mechanisms by which nPM elicits neuroinflammation, and suggest TLR4's involvement in cognitive impairments from air pollution exposure.

\section{Additional files}

Additional file 1: Gene kME relationship between modules: The two shared modules, enriched by both treatments, had strong inverse correlations between the gene-module specific KMEs, which is the eigengene-based connectivity for a gene within a module ( $n P M, R=-0.994 ; \mathrm{LPS}, \mathrm{R}=-0.968$ ). Each gene is given a kME for every module, and then placed into the module of best fit. Thus, individual RNAs with increased expression had strong inverse associations with the eigengene for the turquoise module, while RNAs with decreased expression had strong inverse associations with the eigengene for the blue module. As examples, TNFa had a kME of +0.93 in the blue module, but -0.91 in the turquoise module; again, the subunits NF-KB1 and NF-kB2 had positive kMEs of +0.91 and +0.96 , respectively, in the blue module, but negative kMEs of -0.86 and -0.93 , respectively, in the turquoise module. Together this suggests that the turquoise and the blue modules represent a single network, where the turquoise comprises the decreased RNAs in the network and the blue comprises the increased RNAs. (ZIP $43372 \mathrm{~kb}$ )

Additional file 2: Figure S1. A, LPS-increased RNAs: clustered into networks. 16 nodes, composing 6 networks and 3 individual nodes, are depicted. B, LPS-decreased RNAs: two single nodes are depicted. Colors denote different networks. Nodes with two colors belong to both networks. Each network has one highlighted node (colored text, chosen by experimenter) that best represents network function. The circle size represents the number of genes enriched in the node. The width of connecting lines represents the strength of connectivity between nodes, as measured by kappa score. (ZIP 347 kb)

\section{Funding}

This work was supported by the grants to CEF from the National Institute of Aging R21 AG-040753, R21 AG-050201) and the Cure Alzheimer's Fund and T32AG0037 supporting NCW. These funding bodies had no role in interpreting the data or writing the article.

\section{Availability of data and materials}

Datasets of this study are available as raw data files in the Additional file 1 and will be made available on the Gene Expression Omnibus (GEO) database.

\section{Authors' contributions}

NCW carried out the experiments and data analysis and draft the manuscript. MEL performed microarray data analysis. AH performed data analysis and draft figures. FS and AS contributed to the collection, extraction, and chemical characterization of the nPM samples. CS contributed the nPM samples and designed the nPM collection. TEM participated in the design of studies and manuscript writing. CEF conceived the study, guided the experimental design, and edited the drafts. All authors read and approved the final manuscript.

\section{Competing interests}

The authors declare that they have no competing interests.

\section{Consent for publication}

Not applicable.

\section{Ethics approval}

This study did not include human participants or human subject-derived data. Animal protocols were approved by the University of Southern California Institutional Animal Care and Use Committee.

\section{Publisher's Note}

Springer Nature remains neutral with regard to jurisdictional claims in published maps and institutional affiliations.

\section{Author details}

${ }^{1}$ Leonard Davis School of Gerontology, University of Southern California, Los Angeles, CA, USA. ${ }^{2}$ Department of Human Genetics, David Geffen School of Medicine, University of California Los Angeles, Los Angeles, CA, USA. ${ }^{3}$ Viterbi School of Engineering, University of Southern California, Los Angeles, CA, USA. ${ }^{4}$ Dornsife College, University of Southern California, Los Angeles, CA, USA.

Received: 21 December 2016 Accepted: 29 March 2017

Published online: 14 April 2017

\section{References}

1. Power MC, Weisskopf MG, Alexeeff SE, Coull BA, Spiro 3rd A, Schwartz J. Traffic-related air pollution and cognitive function in a cohort of older men. Environ Health Perspect. 2011;119:682-7.

2. Ranft U, Schikowski T, Sugiri D, Krutmann J, Kramer U. Long-term exposure to traffic-related particulate matter impairs cognitive function in the elderly. Environ Res. 2009;109:1004-11.

3. Wellenius GA, Boyle LD, Coull BA, Milberg WP, Gryparis A, Schwartz J, Mittleman MA, Lipsitz LA. Residential proximity to nearest major roadway and cognitive function in community-dwelling seniors: results from the MOBILIZE Boston Study. J Am Geriatr Soc. 2012;60:2075-80.

4. Zeng Y, Gu D, Purser J, Hoenig H, Christakis N. Associations of environmental factors with elderly health and mortality in China. Am J Public Health. 2010;100:298-305.

5. Wu Y-C, Lin Y-C, Yu H-L, Chen J-H, Chen T-F, Sun Y, Wen L-L, Yip P-K, Chu Y-M, Chen $Y$-C. Association between air pollutants and dementia risk in the elderly. Alzheimers Dement (Amst). 2015;1:220-8.

6. Oudin A, Forsberg B, Adolfsson AN, Lind N, Modig L, Nordin M, Nordin S, Adolfsson R, Nilsson LG. Traffic-related air pollution and dementia incidence in northern Sweden: a longitudinal study. Environ Health Perspect. 2016;124:306-12.

7. Jung CR, Lin YT, Hwang BF. Ozone, particulate matter, and newly diagnosed Alzheimer's disease: a population-based cohort study in Taiwan. J Alzheimers Dis. 2015;44:573-84.

\begin{abstract}
Acknowledgements
We thank Jasmine Zhou for statistical advice on the bioinformatics analysis. 1; TRAP: Traffic-related air pollution; TRIF: Toll/IL-1 receptor domaingene co-expression network analysis

AP-1: Activator protein 1; BACH1: BT3B and CNC homology 1; BACH1: BTB units; Fos: Fos proto-oncogene; GAPDH: Glyceraldehyde 3-phosphate dehydrogenase; GO: Gene Ontology; IFN-y: Interferon gamma; IFN- $\beta$ : Interferon receptor-associated kinase 1 ; IRF: Interferon regulatory factor; JAK2: Janus kinase 2; JNK1/2: C-Jun N-terminal kinase; KC: Chemokine (C-X-C motif) ligand connectivity; LPS: Lipopolysaccharide; MyD88: Myeloid differentiation primary NF-kB: Nuclear factor kappa-light-chain-enhancer of activated B cells; trait loci; SAM: Significance analysis of microarrays; SRF: Serum response factor beta-activated kinase 1; TFT: Transcription factor target; TLR4: Toll-like necrosis factor alpha; TOM: Topological overlap matrix: receptor-associated fassociated factor 3 interacting protein; TRAF6: TNF
\end{abstract}


8. Cacciottolo M, Wang X, Driscoll I, Woodward N, Saffari A, Reyes J, Serre ML, Vizuete W, Sioutas C, Morgan TE, et al. Particulate air pollutants, APOE alleles, and their contributions to cognitive impairment in older women and to amyloidogenesis in experimental models. Transl Psychiatry. 2016. In Press.

9. Ailshire J, Crimmins EM. Fine particulate matter air pollution and cognitive function among older US adults. 2014.

10. Ailshire JA, Clarke P. Fine particulate matter air pollution and cognitive function among U.S. older adults.

11. Perera FP, Tang DL, Wang S, Vishnevetsky J, Zhang BZ, Diaz D, Camann D, Rauh V. Prenatal polycyclic aromatic hydrocarbon (PAH) exposure and child behavior at age 6-7 years. Environ Health Perspect. 2012;120:921-6.

12. Peterson BS, Rauh VA, Bansal R, Hao X, Toth Z, Nati G, Walsh K, Miller RL, Arias F, Semanek D, Perera F. Effects of prenatal exposure to air pollutants (polycyclic aromatic hydrocarbons) on the development of brain white matter, cognition, and behavior in later childhood. JAMA Psychiatry. 2015;72:531-40.

13. Chen JC, Wang X, Wellenius GA, Serre ML, Driscoll I, Casanova R, McArdle JJ, Manson JE, Chui HC, Espeland MA. Ambient air pollution and neurotoxicity on brain structure: evidence from women's health initiative memory study. Ann Neurol. 2015;78:466-76.

14. Casanova R, Wang X, Reyes J, Akita Y, Serre ML, Vizuete W, Chui HC, Driscoll I, Resnick SM, Espeland MA, et al. A voxel-based morphometry study reveals local brain structural alterations associated with ambient fine particles in older women. Front Hum Neurosci. 2016;10:495.

15. Calderon-Garciduenas L, Engle R, Mora-Tiscareno A, Styner M, Gomez-Garza G, Zhu H, Jewells V, Torres-Jardon R, Romero L, Monroy-Acosta ME, et al. Exposure to severe urban air pollution influences cognitive outcomes, brain volume and systemic inflammation in clinically healthy children. Brain Cogn. 2011;77:345-55.

16. Calderon-Garciduenas L, Solt AC, Henriquez-Roldan C, Torres-Jardon R, Nuse B, Herritt L, Villarreal-Calderon R, Osnaya N, Stone I, Garcia R, et al. Long-term air pollution exposure is associated with neuroinflammation, an altered innate immune response, disruption of the blood-brain barrier, ultrafine particulate deposition, and accumulation of amyloid beta-42 and alpha-synuclein in children and young adults. Toxicol Pathol. 2008;36:289-310.

17. Fonken LK, Xu X, Weil ZM, Chen G, Sun Q, Rajagopalan S, Nelson RJ. Air pollution impairs cognition, provokes depressive-like behaviors and alters hippocampal cytokine expression and morphology. Mol Psychiatry. 2011;16:987-95. 973.

18. Morgan TE, Davis DA, Iwata N, Tanner JA, Snyder D, Ning Z, Kam W, Hsu YT, Winkler JW, Chen JC, et al. Glutamatergic neurons in rodent models respond to nanoscale particulate urban air pollutants in vivo and in vitro. Environ Health Perspect. 2011;119:1003-9.

19. Mumaw CL, Levesque S, McGraw C, Robertson S, Lucas S, Stafflinger JE, Campen MJ, Hall P, Norenberg JP, Anderson T, et al. Microglial priming through the lung-brain axis: the role of air pollution-induced circulating factors. Faseb Journal. 2016;30:1880-91.

20. Levesque S, Taetzsch T, Lull ME, Kodavanti U, Stadler K, Wagner A, Johnson JA, Duke L, Kodavanti P, Surace MJ, Block ML. Diesel exhaust activates and primes microglia: air pollution, neuroinflammation, and regulation of dopaminergic neurotoxicity. Environ Health Perspect. 2011;119:1149-55.

21. Campbell A, Oldham M, Becaria A, Bondy SC, Meacher D, Sioutas C, Misra C, Mendez LB, Kleinman A. Particulate matter in polluted air may increase biomarkers of inflammation in mouse brain. Neurotoxicology. 2005;26:133-40.

22. Zhang H, Liu H, Davies KJ, Sioutas C, Finch CE, Morgan TE, Forman HJ. Nrf2-regulated phase II enzymes are induced by chronic ambient nanoparticle exposure in young mice with age-related impairments. Free Radic Biol Med. 2012;52:2038-46.

23. Cheng H, Saffari A, Sioutas C, Forman HJ, Morgan TE, Finch CE. Nano-Scale Particulate Matter from Urban Traffic Rapidly Induces Oxidative Stress and Inflammation in Olfactory Epithelium with Concomitant Effects on Brain. Environ Health Perspect. 2016.

24. Li N, Sioutas C, Cho A, Schmitz D, Misra C, Sempf J, Wang M, Oberley T, Froines J, Nel A. Ultrafine particulate pollutants induce oxidative stress and mitochondrial damage. Environ Health Perspect. 2003;111:455-60.

25. Elder A, Gelein R, Silva V, Feikert T, Opanashuk L, Carter J, Potter R, Maynard A, Ito Y, Finkelstein J, Oberdorster G. Translocation of inhaled ultrafine manganese oxide particles to the central nervous system. Environ Health Perspect. 2006;114:1172-8.

26. Oberdorster G, Sharp Z, Atudorei V, Elder A, Gelein R, Kreyling W, Cox C. Translocation of inhaled ultrafine particles to the brain. Inhal Toxicol. 2004;16:437-45.
27. Cheng H, Davis DA, Hasheminassab S, Sioutas C, Morgan TE, Finch CE. Urban traffic-derived nanoparticulate matter reduces neurite outgrowth via TNFalpha in vitro. J Neuroinflammation. 2016;13:19.

28. Shoenfelt J, Mitkus RJ, Zeisler R, Spatz RO, Powell J, Fenton MJ, Squibb KA, Medvedev AE. Involvement of TLR2 and TLR4 in inflammatory immune responses induced by fine and coarse ambient air particulate matter. J Leukoc Biol. 2009;86:303-12.

29. Becker S, Fenton MJ, Soukup JM. Involvement of microbial components and toll-like receptors 2 and 4 in cytokine responses to air pollution particles. Am J Respir Cell Mol Biol. 2002;27:611-8.

30. Molteni M, Gemma S, Rossetti C. The role of toll-like receptor 4 in infectious and noninfectious inflammation. Mediators Inflamm. 2016;2016:6978936.

31. Tahara K, Kim HD, Jin JJ, Maxwell JA, Li L, Fukuchi K. Role of toll-like receptor signalling in Abeta uptake and clearance. Brain. 2006;129:3006-19.

32. den Hartigh LJ, Lame MW, Ham W, Kleeman MJ, Tablin F, Wilson DW. Endotoxin and polycyclic aromatic hydrocarbons in ambient fine particulate matter from Fresno, California initiate human monocyte inflammatory responses mediated by reactive oxygen species. Toxicol In Vitro. 2010;24:1993-2002.

33. Mueller-Anneling L, Avol E, Peters JM, Thorne PS. Ambient endotoxin concentrations in PM10 from Southern California. Environ Health Perspect. 2004;112:583-8.

34. Juknat A, Pietr M, Kozela E, Rimmerman N, Levy R, Gao F, Coppola G, Geschwind D, Vogel Z. Microarray and pathway analysis reveal distinct mechanisms underlying cannabinoid-mediated modulation of LPS-induced activation of BV-2 microglial cells. PLoS One. 2013;8:e61462.

35. Hwang SH, Choi YG, Jeong MY, Hong YM, Lee JH, Lim S. Microarray analysis of gene expression profile by treatment of Cinnamomi Ramulus in lipopolysaccharide-stimulated BV-2 cells. Gene. 2009;443:83-90.

36. Holtman IR, Raj DD, Miller JA, Schaafsma W, Yin Z, Brouwer N, Wes PD, Moller T, Orre $\mathrm{M}$, Kamphuis W, et al. Induction of a common microglia gene expression signature by aging and neurodegenerative conditions: a co-expression meta-analysis. Acta Neuropathol Commun. 2015;3:31.

37. DiLeo MV, Strahan GD, den Bakker M, Hoekenga OA. Weighted correlation network analysis (WGCNA) applied to the tomato fruit metabolome. PLoS One. 2011:6:e26683.

38. Misra C, Kim S, Shen S, Sioutas C. A high flow rate, very low pressure drop impactor for inertial separation of ultrafine from accumulation mode particles. J Aerosol Sci. 2002;33:735-52.

39. Ning Z, Geller MD, Moore KF, Sheesley R, Schauer JJ, Sioutas C. Daily variation in chemical characteristics of urban ultrafine aerosols and inference of their sources. Environ Sci Technol. 2007:41:6000-6.

40. Liu QH, Babadjouni R, Radwanski R, Cheng H, Patel A, Hodis DM, He SH, Baumbacher P, Russin JJ, Morgan TE, et al. Stroke damage is exacerbated by nano-size particulate matter in a mouse model. Plos One. 2016;11:e0153376.

41. Sardar SB, Fine PM, Mayo PR, Sioutas C. Size-fractionated measurements of ambient ultrafine particle chemical composition in Los Angeles using the NanoMOUDI. Environ Sci Technol. 2005;39:932-44.

42. Holm TH, Draeby D, Owens T. Microglia are required for astroglial Toll-like receptor 4 response and for optimal TLR2 and TLR3 response. Glia. 2012;60:630-8.

43. Pascual $\mathrm{O}$, Ben Achour S, Rostaing P, Triller A, Bessis A. Microglia activation triggers astrocyte-mediated modulation of excitatory neurotransmission. Proc Natl Acad Sci U S A. 2012;109:E197-205.

44. Irizarry RA, Bolstad BM, Collin F, Cope LM, Hobbs B, Speed TP. Summaries of Affymetrix GeneChip probe level data. Nucleic Acids Res. 2003;31:e15.

45. Bolstad BM, Irizarry RA, Astrand M, Speed TP. A comparison of normalization methods for high density oligonucleotide array data based on variance and bias. Bioinformatics. 2003;19:185-93.

46. Irizarry RA, Hobbs B, Collin F, Beazer-Barclay YD, Antonellis KJ, Scherf U, Speed TP. Exploration, normalization, and summaries of high density oligonucleotide array probe level data. Biostatistics. 2003;4:249-64.

47. Langfelder P, Horvath S: WGCNA: an R package for weighted correlation network analysis. BMC Bioinformatics. 2008;9:559.

48. Zhang B, Horvath S. A general framework for weighted gene co-expression network analysis. Stat Appl Genet Mol Biol. 2005;4:17

49. Yip AM. The Generalized Topological OVerlap Matrix for Detecting Modules in Gene Networks. BIOCOMP. 2006.

50. Hong G, Zhang W, Li H, Shen X, Guo Z. Separate enrichment analysis of pathways for up- and downregulated genes. J R Soc Interface. 2014;11:20130950.

51. Bindea G, Mlecnik B, Hackl H, Charoentong P, Tosolini M, Kirilovsky A, Fridman WH, Pages F, Trajanoski Z, Galon J. ClueGO: a Cytoscape plug-in to 
decipher functionally grouped gene ontology and pathway annotation networks. Bioinformatics. 2009;25:1091-3.

52. Lehnardt S, Lachance $C$, Patrizi S, Lefebvre S, Follett PL, Jensen FE, Rosenberg PA, Volpe JJ, Vartanian T. The toll-like receptor TLR4 is necessary for lipopolysaccharide-induced oligodendrocyte injury in the CNS. J Neurosci. 2002;22:2478-86.

53. Xiong Q, Ru Q, Chen L, Yue K, Tian X, Ma B, Liu L, Wu R, Xu C, Pi M, Li C. Combined effects of fine particulate matter and lipopolysaccharide on apoptotic responses in NR8383 macrophages. J Toxicol Environ Health A. 2015;78:443-52.

54. Inoue K, Takano H, Sakurai M, Oda T, Tamura H, Yanagisawa R, Shimada A, Yoshikawa T. Pulmonary exposure to diesel exhaust particles enhances coagulatory disturbance with endothelial damage and systemic inflammation related to lung inflammation. Exp Biol Med (Maywood). 2006; 231:1626-32.

55. Kleinman MT, Araujo JA, Nel A, Sioutas C, Campbell A, Cong PQ, Lia H, Bondy SC. Inhaled ultrafine particulate matter affects CNS inflammatory processes and may act via MAP kinase signaling pathways. Toxicol Lett. 2008; 178:127-30

56. Tak PP, Firestein GS. NF-kappaB: a key role in inflammatory diseases. J Clin Invest. 2001;107:7-11.

57. Gabehart K, Correll KA, Loader JE, White CW, Dakhama A. The lung response to ozone is determined by age and is partially dependent on toll-Like receptor 4. Respir Res. 2015;16:117.

58. Ferwerda B, McCall MB, Verheijen K, Kullberg BJ, van der Ven AJ, Van der Meer JW, Netea MG. Functional consequences of toll-like receptor 4 polymorphisms. Mol Med. 2008;14:346-52.

59. Wang $Y$, Ge P, Zhu Y. TLR2 and TLR4 in the brain injury caused by cerebral ischemia and reperfusion. Mediators Inflamm. 2013;2013:124614.

60. Wang YJ, Chen G, Yu XD, Li YC, Zhang L, He ZZ, Zhang NN, Yang XP, Zhao YS, Li N, Qiu H. Salvianolic acid B ameliorates cerebral ischemia/reperfusion injury through inhibiting TLR4/MyD88 signaling pathway. Inflammation. 2016;39:1503-13.

61. Brea D, Blanco M, Ramos-Cabrer P, Moldes O, Arias S, Perez-Mato M, Leira R, Sobrino T, Castillo J. Toll-like receptors 2 and 4 in ischemic stroke: outcome and therapeutic values. J Cereb Blood Flow Metab. 2011;31:1424-31.

62. Kim SH, Knight EM, Saunders EL, Cuevas AK, Popovech M, Chen LC, Gandy S. Rapid doubling of Alzheimer's amyloid-beta 40 and 42 levels in brains of mice exposed to a nickel nanoparticle model of air pollution. F1000Res. 2012;1:70.

63. Block ML, Calderon-Garciduenas L. Air pollution: mechanisms of neuroinflammation and CNS disease. Trends Neurosci. 2009;32:506-16

64. Walter S, Letiembre M, Liu Y, Heine H, Penke B, Hao W, Bode B, Manietta N, Walter J, Schulz-Schuffer W, Fassbender K. Role of the toll-like receptor 4 in neuroinflammation in Alzheimer's disease. Cell Physiol Biochem. 2007;20:947-56.

65. Jin JJ, Kim HD, Maxwell JA, Li L, Fukuchi K. Toll-like receptor 4-dependent upregulation of cytokines in a transgenic mouse model of Alzheimer's disease. J Neuroinflammation. 2008;5:23.

66. Qin Y, Liu Y, Hao W, Decker Y, Tomic I, Menger MD, Liu C, Fassbender K. Stimulation of TLR4 attenuates Alzheimer's disease-related symptoms and pathology in tau-transgenic mice. J Immunol. 2016;197(8):3281-3292.

67. Kim S, Becker J, Bechheim M, Kaiser V, Noursadeghi M, Fricker N, Beier E, Klaschik S, Boor P, Hess T, et al. Characterizing the genetic basis of innate immune response in TLR4-activated human monocytes. Nat Commun. 2014;5:5236.

\section{Submit your next manuscript to BioMed Central and we will help you at every step:}

- We accept pre-submission inquiries

- Our selector tool helps you to find the most relevant journal

- We provide round the clock customer support

- Convenient online submission

- Thorough peer review

- Inclusion in PubMed and all major indexing services

- Maximum visibility for your research

Submit your manuscript at www.biomedcentral.com/submit
Biomed Central 